\title{
La arquitectura teatral a través de las pruebas de pensado en la Real Academia de Bellas Artes de San Fernando
}

\author{
Juana María Balsalobre García *
}

\begin{abstract}
RESUMEN
La importancia histórica de la Academia

$y$ su influencia, en cuanto al hecho arquitectónico, se halla en la labor de la

Comisión de Arquitectura. Ésta junta desempeñó la línea motriz del pensamiento académico. En resumen, el cuerpo de esta investigación se basa en el estudio de tres proyectos de teatros censurados por dicha Comisión. El interés de los planos y de los manuscritos es significativo, porque por un lado proporcionan documentación inédita en la actualidad, sobre tres teatros proyectados en España, por el otro encierran el juicio de valor que motivaron en la Academia. En tal contexto cabe señalar la postura abierta de la Academia, pues no se trataba de defender una curva para la planta de la sala, sino más bien la derivada de resolver el conjunto arquitectónico adecuadamente a su función.
\end{abstract}

\section{ABSTRACT}

Thanks to its Architect Commission the Real Academy of San Fernando was basic to the ulterior development of the academic thought. The main object of the investigation is based on the study of the three theatre projects censored by that Commission. The significance of the plans and manuscripts is important because they show documentation unknown nowadays about the theatres planned in Spain in the Nineteenth Century and because they contain the architectural ideas of the Academy. We must point out the advanced ideas of the Academy in this context because it tried to resolve the architectural group appropriately to its function.

* Tercer Cíclo. Departamento de Historia del Arte. UNED. 
Nuestro edificio-teatro en el siglo XIX presenta, en comparación al italiano 0 al francés, una constatada diferencia centrada en la escasa aportación, en la época, de publicaciones de análisis comparativo sobre el tema. Sin embargo, el hecho de no participar directamente en el debate europeo, no indica una falta de teoría ni tampoco de una práctica arquitectónica de la que tenemos numerosos ejemplos en nuestras ciudades. En este contexto, se debe destacar el importantísimo papel desempeñado por la Academia de San Fernando. Éste se refleja ampliamente en la riqueza documental que guarda en su Archivo y en el correspondiente a dibujos y planos.

Dichas fuentes permiten, por un lado el estudio de la teoría y la praxis de la tipología teatral y por otro encierran el juicio de valor que sus diseños motivaron en la Academia. Por ello sirven para reconstruir el pensamiento académico sobre la arquitectura teatral. Los manuscritos discursivos se separan en dos clases de documentos, que a su vez son interdependientes por el tema: el edificio-teatro. En un apartado se agrupan las memorias facultativas y en el otro las disertaciones académicas. Las primeras las escribían los aspirantes al titulo de arquitecto para presentarlas como prueba de pensado. Este manuscrito se acompañaba de los planos correspondientes a la obra proyectada por el aspirante a arquitecto '. El segundo grupo forma parte de los discursos redactados para obtener el gracio de académico de mérito ${ }^{2}$ por la Arquitectura de la Real Academia de Bellas Artes de San Fernando.

Un hecho decisivo, para calibrar la importancia histórica de la institución madrileña y su influencia, se halla en la labor de la Comisión de Arquitectura. Esta junta desempeñó, en cuanto al hecho arquitectónico, la línea motriz del pensamiento académico. Sus miembros se ocuparon de estudiar todo lo referido a la Arquitectura e informar a la Academia de las cuestiones debatidas y de sus dictámenes relativos, entre otros asuntos, al estudio de los expedientes de los aspirantes a los títulos de académicos, arquitectos, maestros de obras. Dentro de su importante quehacer hay que considerar su labor determinante en las obras pensadas para ser construidas en las diversas ciudades españolas y enviadas para su aprobación.

En este sentido tiene un extraordinario interés el listado de aspirantes a arquitectos con la relación de los temas de examen realizado por M.․ㅡ del Rosario SANTAMARÍA ALMOLDA: “Bases documentales para el estudio de la teoría arquitectónica (1814-1858) en la Real Academia de Bellas Artes de San Fernando». En Espacio, Tiempo y Forma, serie VII, H. ${ }^{\text {a }}$ del Arte, t. 9, UNED., 1996, págs. 219-247.

2 Balsalobre García, Juana María: «Elementos clásicos e innovadores en los discursos académicos sobre el teatro (1825-1844)". En Los clasicismos en el arte español. X Congreso del CEHA. Departamento de Historia del Arte U.N.E.D., Madrid, 1994, págs. 367-371. 
La elección de los tres proyectos de teatro diseñados por Luciano de lbarra, Josef Peterrade y Cirilo Salinas, aspirantes al título de arquitecto, son eslabones de la cadena que define la importancia del tema en la Academia. Tales diseños son un claro ejemplo del lenguaje que se estaba planteando en las primeras décadas del siglo XIX respecto a la tipología teatral, ideal y constructiva. Además permiten mostrar tanto las características tipológicas de tales obras como la particular visión de sus autores e igualmente la imagen académica.

\section{LA COMISIÓN DE ARQUITECTURA: NEXO ENTRE LO BUROCRÁTICO Y LO CREATIVO}

En los primeros años del siglo XIX la Academia de Bellas Artes de San Fernando era un organismo que tenía sus raíces inmediatas en el siglo XVIII. Las líneas rectoras determinadas en su origen, como institución contrapuesta a los gremios, se plasmaron en la creación de la Junta de Comisión de Arquitectura ${ }^{3}$. En su labor fue combinando los elementos de debate interno con el estudio y censura de todas las obras públicas enviadas a la Academia. Su andar continuado condujo a un ajuste progresivo a los cambios y a las nuevas condiciones de la sociedad. No obstante, hay que destacar la ruptura que supuso, en todos los ámbitos de la sociedad española, la Guerra de la Independencia. En el arquitectónico, tal hecho, interrumpió y retardó, prácticamente una década, el normal funcionamiento académico tanto en el área docente como en la censora.

Dentro de las consecuencias inmediatas del periodo bélico, además de señalar la interrupción de las actividades académicas, hay que mencionar las destrucciones provocadas por la guerra que obligaron a una política de reconstrucciones. En concreto a la puesta en práctica de los proyectos de obras públicas más necesarios. Estos factores explican, respecto a los diseños de teatro, un vacío en un periodo dilatado de más de una década tanto en lo que concierne a la elección de esta tipología por los aspirantes a arquitectos, como en la presentación de los mismos a la censura de la Real Academia para su construcción.

\footnotetext{
García Melero, José Enrique: «Arquitectura y burocracia: el proceso del proyecto en la Comisión de Arquitectura de la Academia (1786-1808)". En Espacio, Tiempo y Forma, Serie VII, Historia del Arte, t. 4, 1991, págs. 283- 348. «Juan de Villanueva y los nuevos planes de estudio" en Renovación, Crisis. Continuismo. La Real Academia de San Fernando en 1792. Madrid, Real Academia de Bellas Artes de San Fernando, 1992. «El debate académico sobre los exámenes para las distintas profesiones de la Arquitectura (1781-1783)". Espacio, Tiempo y Forma, Serie VII, H. del Arte, t. 6. 1993, págs. 325-378.
} 


\subsection{Requisitos necesarios para las pruebas de examen de académicos de mérito y de arquitectos}

Tanto las primeras como las segundas fueron propuestas por la Academia y reguladas por Reales órdenes. La R.O. de 27 de mayo de 1800 prevenía que el arquitecto aspirante a académico debía escribir «un discurso o disertación sobre algún punto del arte que le señale la Academia» ${ }^{4}$. El interés de este organismo por estos temas se constata en el estudio que hizo sobre ellos. La propuesta de la Real Academia al rey Carlos IV para "agilizar las pruebas previas que debian hacer los pretendientes al título de arquitecto " ${ }^{5}$ fue ratificada, un mes después, por Real Orden de 29 de julio de 1801. Posteriormente, el rey Fernando VII renovaba lo dictaminado en las anteriores reales disposiciones con la Real Cédula de 2 de octubre de $1814^{6}$. En la que se hacía saber a todas las instituciones y a sus representantes, que en el párrafo tercero del estatuto treinta y tres de la Academia de San Fernando, se mandaba que ninguna de aquellas pudiese dar atribuciones para ejercer la Arquitectura y que además debían enviar los proyectos para la aprobación académica, según lo ordenado en las R.O de 23 de noviembre de 1777 y 20 de diciembre de 1798.

Por otra parte, la Academia puso en conocimiento de su majestad, el problema de las destrucciones de obras públicas y particulares a causa de la guerra y la necesidad de su reconstrucción. Pero la falta de profesores aprobados ${ }^{7}$ creaba una situación de competencias, denunciada por los profesionales autorizados en las diferentes provincias y también por los representantes de las mismas ${ }^{8}$, por ello proponía al rey el restablecimiento

4 ARCHIVO REAL ACADEMIA DE SAN FERNANDO (A.R.A.S.F). Leg.17-5/1. «Disposiciones de la Acad para el examen de las disertaciones de los Academicos arquitectos". Además de lo prevenido por la R.O. la Academia quería fijar quienes debían ocuparse del examen, «y pues que se trata por lo comun de uno que es ya Maestro Arquitecto... parece que debe dar la razon en la misma Junta de examen para la recepción de Mtros Arquitectos, compuesta a saber del Sr. Viceprotector, o Presidente, del Director gral, de los dos Directores y dos Tenientes de Arquitectura, y de los Directores de Matemáticas, con asistencia del Srio de la Acad ${ }^{9} . .$. Para que los examinadores... puedan hacer al examinando preguntas o reparos con el debido conocimiento... se hace forzoso que con alguna anticipacićn hayan visto el escrito... sea que se pasen copias o que el original corra de mano en mano debe fijarse un término que pueda ser de dos o tres días..." Madrid 3 de abril de 1814.

A.R.A.S.F. Leg. $49-10 / 1$

A.R.A.S.F. Leg. $17-3 / 1$

Otra consecuencia de la guerra fue que el número de profesionales de la arquitectura fue disminuyendo además de por causas naturales porque en este periodo tampoco hubo examenes, y no salieron nuevas promociones.

A.R.A.S.F. Libro de Actas de Comisión de Arquitectura. 140/3. Junta de 28 de febrero de 1816, fol. 76 . Junta de 9 de marzo, fol. 76 rev. y Junta de 16 de marzo, fol. 77 rev. 
de las cuatro clases de facultativos que existieron en $1796{ }^{9} \mathrm{y}$ que en ese año quedaron reducidos a arquitectos y académicos de mérito. Esta petición fue ratificada por la R. O. de 28 de agosto de $1816^{10}$. Paralelamente su majestad quería que la Academia definiera claramente las competencias de cada una de las categorías para evitar las posibles infracciones.

Esta institución analizó y formuló una "ordenanza artística" "partiendo del grado superior al inferior. En el capítulo primero recogió en nueve artículos las atribuciones de los académicos de mérito. Para obtener este título era necesario ser arquitecto y haber demostrado el grado de conocimiento arquitectónico y dominio del dibujo con el envío de varias obras a la censura, bien por encargo o como proyectos de su invención, para que ésta pudiese juzgar su perfeccionamiento ${ }^{12}$. Una vez cubiertos estos requisitos, el pretendiente solicitaba el examen y si era aceptado el viceprotector le sorteaba los temas de disertaciones. De estos tres asuntos, el arquitecto elegía uno que preparaba, escribía y presentaba a la Academia para que ésta le señalase el día y la hora para su defensa y examen.

El tema había sido propuesto y estudiado por la junta de Comisión de Arquitectura del día 2 de diciembre de 1803 y aprobado por la Academia, tratándose en otras juntas, como la del 27 de mayo de 1806, en la que sus miembros eligieron los títulos de las materias para formar el legajo correspondiente y acordaron ir añadiendo otros. Esta cuestión se paralizó hasta el año 1814 en que se reunió la junta el 8 de diciembre para tratar exclusivamente de las disertaciones. En la sesión del 1 de febrero de 1815 la Comisión de Arquitectura decidió preparar un segundo libro con los enunciados de los contenidos para la prueba de repente en la que los arquitectos aspirantes a académicos debían demostrar su dominio del dibujo ${ }^{13}$. En conjunto la renovación de las materias continuó siendo debatida ${ }^{14}$

\& Sin embargo la Academia reconsideró esta división y en la junta de 12 de enero de 1817, la Comisión acordó que en la clase de Arquitectura se redujese a tres clases: Académicos de mérito, arquitectos y maestros de obras. A.R.A.S.F. Libro de Actas de Comisión de Arquitectura. 140/3, tol. 108.

10 A.R.A.S.F. Leg. 17-3/1.

A.R.A.S.F. Leg. 17-3/1. Estatutos. Ordenanza artística.

12 A.R.A.S.F. Libro de Actas de Comisión de Arquitectura 140/3. Junta de 6 de julio de 1815. fol. 60 .

13 Ibidem. Junta de $1^{\circ}$ de febrero de 1815. La finalidad era «reunir un completo Estudio de Arquitectura desde los cinco ordenes de Viñola, Templos de Vitruvio del antiguo Desgodez y otros autores, que nadie mejor podrá hacerlo que los que aspiren al grado de Académicos de merito de esta clase". Fol. 50.

${ }_{14}$ Ibidem. Junta de 28 de febrero de 1816 , fol. 75 rev. Junta de 9 de marzo, fol. 77 . Junta de 16 de marzo, fol. 79 anv. La importancia del asunto se alargó y en la junta de $1^{\circ}$ de abril de 1818 se refleja la opinión de la Academia que en junta ordinaria había decidido continuar la ampliación 
en la década siguiente ${ }^{15}$ tanto para los exámenes de académicos como para los arquitectos y maestros de obras.

Una vez aprobado, el académico tenía las mismas prerrogativas que los hijosdalgos. Su entrada en esta institución le habilitaba para participar en las juntas públicas y generales con voz y voto y con los mismos derechos si era convocada su presencia en las juntas ordinarias. También podía asistir a las salas de estudios de la Academia y ejercer como profesor, cuando fuese requerido, para cubrir las posibles ausencias o las vacantes de sus directores o tenientes. En cuanto a las labores profesionales no tenía ninguna limitación y en lo que concernía a los nombramientos para arquitectos mayores tenían la preferencia.

El capítulo segundo de los estatutos se refería a los arquitectos, en el primer artículo se señalaba la correspondencia entre las facultades, que este grado concedía y los estudios adoptados por la Academia. Si no era discípulo de este organismo podía presentarse a este título haciendo constar dónde y qué estudios había realizado. Tanto el pretendiente como el discípulo debían presentar el certificado de haber practicado la arquitectura, por lo menos dos años, con un académico o un arquitecto. Igualmente estaban obligados a presentar las certificaciones de "su conducta, providad y honradez" en secretaría junto a la solicitud y a su obra de pensado, es decir, los planos de su invención de un edificio de primer orden, en planta, fachada y sección, con la correspondiente memoria facultativa. En la que el aspirante debía exponer los motivos de su elección, el método de construcción, los materiales, el presupuesto detallado del coste y la posible ubicación si se construyese.

Después de estudiar el expediente del aspirante, la Comisión de Arquitectura notificaba el dictamen a la Academia. Si era favorable, en junta ordinaria, se sorteaban tres números correspondientes a los temas del libro de pruebas de repente. Al día siguiente se le comunicaban al pretendiente, que elegía uno de los asuntos para realizar dicha prueba. El examinado, sin salir de la Academia, podía consultar los libros de Arquitectura de la biblioteca. Disponía de quince horas (de las siete de la mañana a las diez de la noche) para trazar el diseño elegido, en el que debía dibujar los perfiles y marcar las sombras, en tinta china, en la fachada y corte.

del número de temas para académicos y además que la Comisión preparase asuntos para examen de maestros de obras.

15 A.R.A.S.F. Libro de Actas de Comisión de Arquitectura, 141/3. Junta de 7 de julio de 1826 «Presenté los libros de programas que a la suerte se mandan ejecutar a los aspirantes a Mros Arquitectos y de obras, y se determinó por el Sr. Presidente que para su reconocimto. se fijasen los jueve; de las siguientes semanas hasta su conclusión" fol. 60 rev. 
El día señalado por la Academia tenía lugar el tercer ejercicio. La junta de examen estudiaba la prueba de pensado, la de repente y formulaba al pretendiente las preguntas, que consideraba necesarias sobre la teoría y la práctica arquitectónica, para conocer el grado de aptitud del futuro arquitecto. Una vez finalizado el examen, debía abandonar la sala. Tras la votación secreta se dictaminaba su aprobación, que era ratificada, en junta ordinaria, por la Academia.

Una vez obtenido el título, el arquitecto no tenía ninguna limitación para ejercer su profesión. Únicamente, en la cuestión referente a un nombramiento, el académico de mérito contaba con la preferencia por lo demás tenía las mismas ventajas y los mismos derechos. Todos ellos se detallan en el artículo 14 de la mencionada ordenanza artística ${ }^{16}$.

\subsection{Proyectos de teatro formados por Luciano de Ibarra (1826), Josef Peterrade (1830) y Cirilo Salinas (1832)}

Estos diseños son tres ejemplos del estudio ${ }^{17}$ de los más de veinte proyectos que tratan el edificio-teatro en un periodo, que abarca los primeros años del siglo XIX y se extiende hasta el año 1855. El nexo unificador se halla en que todos ellos fueron formados por sus autores para ser presentados a las pruebas de examen para el grado de arquitecto, tanto de repente como de pensado.

Concretamente, la elección de las obras proyectadas por lbarra, Peterrade y Salinas se basa en la proximidad cronológica de su presentación a la institución madrileña para la primera prueba del examen de arquitecto. $Y$ al mismo tiempo se han seleccionado por las particularidades tipológicas, que permiten mostrar tres modelos de teatro de gran interés para nuestra arquitectura teatral. No obstante se debe señalar, que no se trata de nuevos modelos pero sí de tres concepciones plasmadas en un interesante estudio del edificio más o menos detallado, que se resuelve acertadamente en los planos.

El tema no sólo se plantea desde la perspectiva de los autores de los diseños, sino que atañe también al estudio y dictamen de la Comisión de

16 También señalaba las atribuciones de los maestros de obras y de los aparejadores. A.R.A.S.F. leg. 17-5/1.

${ }_{17}$ Este importante grupo de proyectos de teatro forman parte de la investigación, que como tesis doctoral he finalizado. La imagen académica del teatro español decimonónico. El teatro y sin censura en La Real Academia de Bellas Artes de San Fernando (1800-1870), dirigida por el Dr. José ENRIQUE García MELERO y defendida en la UNED, Madrid, 1997, publicada en microfilm por el Servicio de Investigación de la UNED, Madrid, 1998. 
Arquitectura aunque en los tres casos fue favorable a los tres proyectos. Este dato muestra, en este periodo, la visión abierta de la Academia al aprobar las citadas obras. Éstas fueron formadas, teniendo en cuenta el conjunto del edificio y resueltas en todas sus partes. Aunque de forma particular, por cada uno de los aspirantes, tanto en el planteamiento del dibujo, como en la exposición escrita. La vertiente más práctica de la visión tipológica la encarna Josef Peterrade. La intermedia aflora en la conjugación teórico-práctica que Luciano de lbarra presenta en su memoria facultativa. Sin embargo la exposición escrita por Cirilo Salinas es la más completa. Este aspirante analiza cada uno de los puntos arquitectónicos específicos de esta tipología y también las premisas básicas, que están en la base del estudio de la óptica y la acústica ${ }^{18}$.

\subsubsection{Proyecto de teatro ideado en 1826 para la ciudad de Bilbao}

Su autor, Luciano de Ibarra nació en 1800 en Bilbao, fue discípulo del arquitecto Agustín de Humarán y solicitó a la Real Academia de San Fernando ser admitido a las pruebas de examen para acceder al grado de arquitecto. Pero las obras remitidas a la citada institución fueron desestimadas por la Comisión de Arquitectura ${ }^{19}$. Sin embargo, la tercera vez presentó como obra de pensado el proyecto de un «Magnifico Teatro» ${ }^{20}$, que le permitió el paso a las demás pruebas y ser aprobado de arquitecto el 4 de junio de 1826.

La memoria facultativa de su proyecto de teatro es bastante pragmática, en la introducción valoró la importancia de la arquitectura definiéndola como la experiencia y precisión necesaria para resolver en la práctica un proyecto. En primer lugar, expuso la ubicación del edificio en los «arraba-

18 A pesar del interés que tiene el estudio de la teoría, en la aplicación de los preceptos de la óptica y la acústica, para la defensa de cada una de las curvas, aquí no se van a tratar, por una razón de espacio.

19 A.R.A.S.F. Leg. 68-3/4. Informe Comisión de Arquitectura. Madrid, 6 agosto de 1825. En la junta del 29 de julio de 1825 la Comisión estudió los dos primeros proyectos: «Un Hospital para ambos sexos» y una "Catedral para el centro de una población». Fueron desestimadas porque no venían acompañados de los correspondientes informes facultativos en los que debían reflejarse el coste de las obras, "y no haber llenado las ideas los referidos diseños fue de dictamen se le diga complete el expediente, aconsejandole la presentación de nueva obra mas conforme, proporcionada y analoga al buen gusto de Arquitectura». Se presentó por segunda vez enviando un Proyecto de Palacio para un magnate o gran señor, visto por la Comisión de Arquitectura en la junta del 16 de noviembre de 1825, informó que «no hallando suficiente merito en estos diseños no pudo aprobarlos".

20 Ibidem. Instancia de Luciano de lbarra firmada en Madrid el 28 de febrero de 1826. 


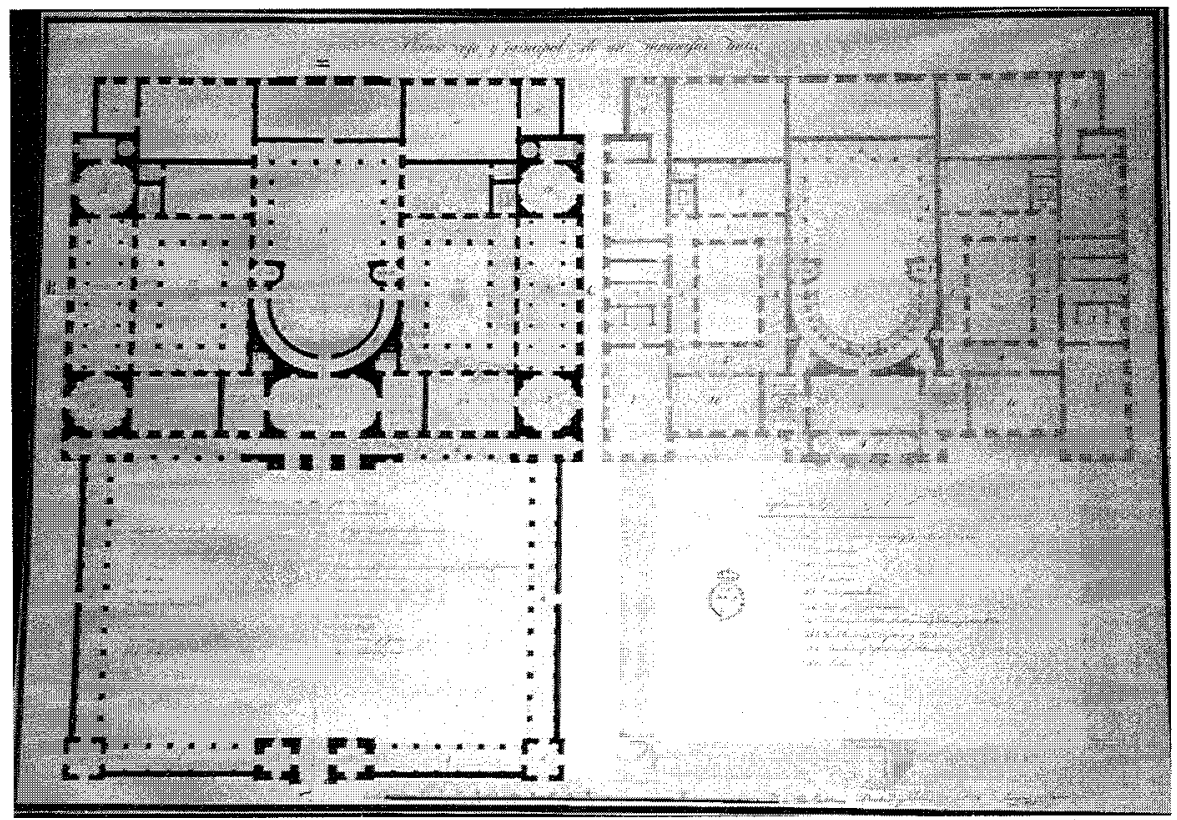

Lámina I. Luciano de Ibarra. Planta baja y principal de un magnífico Teatro. 1826. Academia de San Fernando. A-3300.

les» pues consideraba, que una gran ciudad debía tener más de un teatro. Seguidamente se refirió a su forma y dimensiones. Igualmente comentó los preceptos de la óptica, la acústica y la necesaria solidez, comodidad y belleza como principios inherentes al edificio tanto en el interior como en el exterior. El cuerpo de su informe facultativo se sintetiza en el método constructivo, la clase de materiales y el cálculo del coste de su obra. Este conjunto nos proporciona algunos de los datos que permiten puntualizar el lenguaje de su proyecto.

El esquema compositivo de la planta baja (lámina l) está trazado en un paralelogramo rectángulo, marcado por el eje simétrico longitudinal del edificio cuyo centro es el teatro. A los lados se proyectan las dependencias accesorias. Su fachada principal se abre a una plaza porticada. Ésta enmarca el primer rectángulo de dicha línea $A B$, en la que está diseñada la entrada (1). A la derecha de la misma se ubica la dependencia para el cuerpo de guardia (2) y a la izquierda, la correspondiente a la distribución de boletos (3). En los ángulos se disponen los vestíbulos (5) abiertos en los cuatro lados para permitir el acceso del exterior a la galería que conduce a la fachada principal y a los vestíbulos octogonales. 
Estos elementos arquitectónicos enmarcan la espacialidad del teatro porque tienen accesos independientes, que se abren a los salones de juego (21) y a los cafés (20), cada uno ornamentado con dieciséis columnas. En la parte posterior de esta crujía se proyectan, en sendos octógonos la pastelería (18) y la botillería. El nexo de estos espacios y el teatro está dominado por la disposición de los dos patios porticados (22) pensados como magnificas áreas de recreo en las que se podía, a su vez transitar a cubierto. En el centro de los patios se hallan los pozos ubicados en el eje BC, proyectados además por considerarlos necesarios en caso de un incendio.

A partir del eje central la organización de cada una de las partes del teatro se resuelve en el plano destacando en primer lugar el saliente de la fachada principal marcada por las tres puertas de entrada, que dan acceso a la antesala (6) y a su vez, permite el ingreso a las escaleras principales (7) y a los corredores (10) del perímetro de la sala, con una puerta principal en el eje $A B$ y dos laterales en la línea $\mathrm{BC}$. El número 8 de la explicación del plano se refiere al patio del auditorio, su perímetro está delineado en graderío (9). A pesar de la idea plasmada en esta disposición, como recurrencia clásica, se trata de una concepción moderna de la tipología, también repite la citada distribución en el último piso de la vertical de la sala, intercalando entre estos dos espacios una serie de cuatro ordenes de palcos, como se aprecia en la Sección AB (lámina II).

La curva del auditorio ${ }^{21}$ forma un semicírculo escasamente prolongado por el truncamiento, que supone el trazado de la embocadura cuyos cierres laterales están ocupados por los huecos de las escaleras de caracol (12) para subir a los corredores. Por lo que respecta al escenario (11) hay que mencionar el diseño de los hombros y de la parte posterior y también el trazado a manera de pórtico con una serie de puertas, que se abren a los vestuarios de hombres (13) en el lado derecho, mientras el izquierdo se reserva para los camerinos de las mujeres (14). En la crujía posterior se distribuye en el centro el almacén de las decoraciones (17), en los laterales las salas de ensayos (16) y en los ángulos de cierre las dependencias para guardar la pintura (15).

El esquema compositivo de la planta del piso principal (lámina I) se proyecta, a partir del cuerpo saliente de la fachada sobre el que se coloca

21 Ibidem. Memoría facultativa del proyecto de «un magnífico Teatro» firmada por Luciano de Ibarra, Madrid 27 de febrero de 1826 «la forma interior del Teatro de figura semicircular, pero prolongada como una tercera parte de radio hacia la escena, para darle mayor capacidad y estrechar la embocadura de la referida escena por cuanto me ha parecido mas a proposito en virtud de lo que la experiencia dicta, a pesar de que algunos opinan ser la mejor la eliptica". 


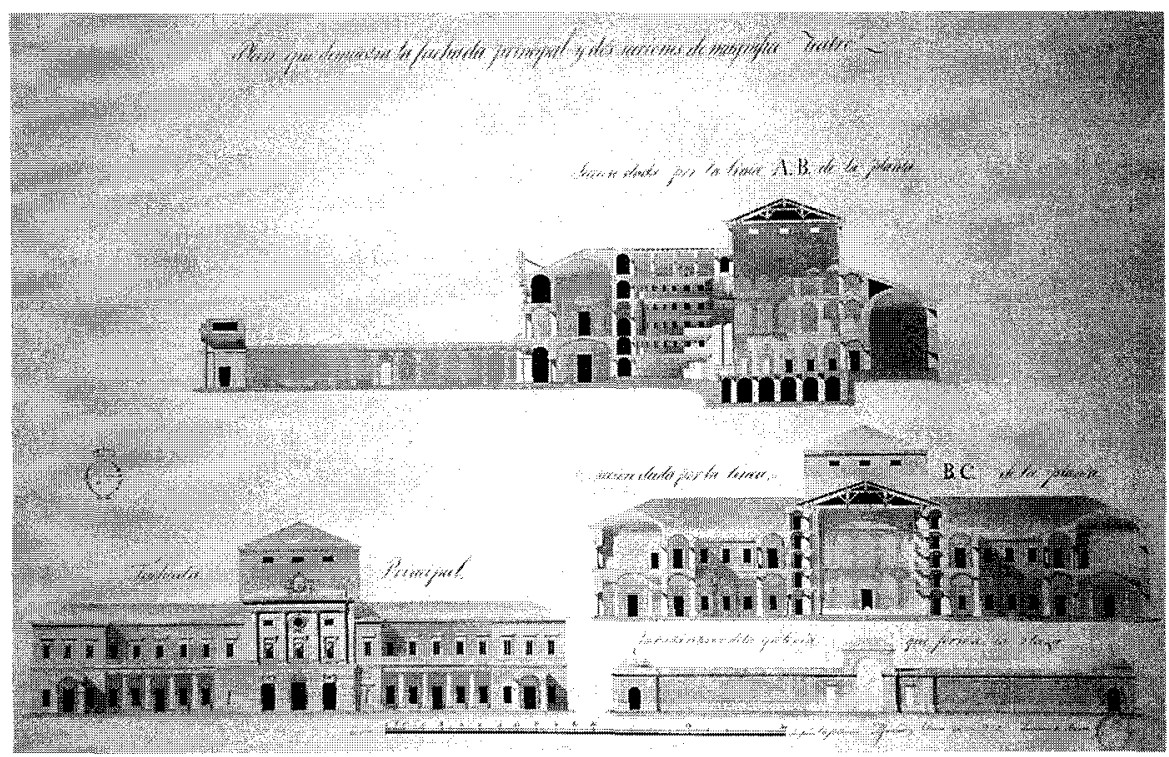

Lámina II. Luciano de Ibarra. Fachada principal. Sección dada por la línea AB. Sección dada por la línea BC y Fachada exterior de la galería que forma la Plaza. 1826. Academia de San Fernando. A-3301.

una pieza de desahogo para la presidencia (1) con una antesala (2) central y dos salas laterales (10) todas ellas amplían los recintos diseñados para los entreactos. Las escaleras (3) en esta piso desembocan directamente en dos pasillos abiertos a los corredores (4) de la sala. Estos espacios distribuidores se ubican en el plano, alrededor de los patios, en el perímetro del escenario y rodeando los palcos particulares (5) así como el central reservado a la presidencia (6). Las escaleras, que enmarcan la embocadura, permiten el acceso al corredor del auditorio y al dispuesto en el escenario, para el manejo de la maquinaría teatral. El resto de las dependencias laterales se señalan en el plano, con el número 8 las habitaciones de los cafeteros y con el 9 las correspondientes a los pasteleros.

La fachada principal (lámina II) presenta una solución de edificio de primer orden. El acento relevante recae en el volumen arquitectónico central formado por tres alturas. En la planta baja el pórtico, que sobresale de la línea de la galería, se resuelve con un paramento roto por las tres aberturas de las puertas. A la reiteración en el tratamiento visual de los huecos adintelados laterales, se añade en la planta baja el ordenamiento de las columnas, que resuelven la galería de una manera más relevante dentro 
del esquema compositivo del conjunto, contraído por los volúmenes de las esquinas, que se abren a las líneas porticadas de la plaza.

Por otra parte, ese espacio abierto tiene un extraordinario interés como elemento de desahogo para el acceso de los asistentes al teatro y también determina la preocupación urbanística en su relación con la ciudad. Sin embargo, Luciano de lbarra simboliza las connotaciones de la plaza a partir de una concepción unitaria, trazándola como parte del conjunto arquitectónico con una dualidad conjugada en la idea de lugar abierto y cerrado de un espacio lúdico.

En el piso principal se disponen dos series de tres vanos, los inferiores participan de la horizontalidad y composición de los laterales con los balcones como elementos diferenciadores; los superiores, junto con el frontón definen una rica ornamentación, que equilibra la gran masa compacta posterior, característica necesaria y repetida en la tipología teatral. Así como la disposición de las cuatro columnas entregadas, que por un lado enmarcan la espacialidad vertical y por otro resuelven la recurrencia a la monumentalidad de la portada.

\subsubsection{Proyecto de teatro para la ciudad de Santander}

Su autor, Josef Peterrade nacido en Cádiz, era maestro de obras aprobado por la Academia de San Fernando y mayor de la ciudad de Santader. Cuando solicitó presentarse al grado de arquitecto tenía cuarenta y tres años. Además contaba con una larga experiencia en la dirección de importantes obras en la ciudad santaderina, enviadas a la censura de la Academia de Bellas Artes de San Fernando. Sin embargo, en la relación de las mismas, expuesta en la instancia ${ }^{22}$ no hizo mención a su anterior proyecto de teatro ${ }^{23}$, enviado a esta institución y aprobado con algunas observaciones.

Antes de comunicar a la Academia su deseo de presentarse a examen, pidió al Ayuntamiento de Santander la licencia para trasladarse a Madrid cuatro meses ${ }^{24}$ para asistir a las clases de Arquitectura de la

22 A.R.A.S.F. Leg. 9-4/2. Instancia firmada por Josef Peterrade. Madrid, 6 de marzo de 1830.

23 Balsalobre García, Juana María: La imagen académica del teatro español decimonónico. El teatro y su censura en la Real Academia de Bellas Artes de San Fernando. Memoria de investigación leida en la UNED., octubre de 1993 y dirigida por el Dr. D. José Enrique García Melero. Dicho proyecto pensado para edificarlo en la ciudad de Santander tiene puntos comunes respecto a la solución arquitectónica con el aquí comentado. En síntesis, se trata de una repetición del primero.

${ }_{24}$ A.R.A.S.F. Leg. 9-4/2. Certificación firmada por el secretario del Ayuntamiento de Santander el 18 de enero de 1830 . 
Academia ${ }^{25}$. Presentó como obra de pensado el proyecto de un Teatro, el presupuesto y los planos, pero no adjuntó, la memoria facultativa. La Comisión de Arquitectura en junta celebrada el 9 de marzo de 1830, informó favorablemente, y en junta ordinaria del día 14 se efectuó el sorteo de los tres asuntos para la prueba de repente. El aspirante siguiendo las normas estipuladas eligió uno ${ }^{26}$. Una vez realizado, se reunió la junta de examen, en este ejercicio presencial el examinado respondió a todas las preguntas formuladas tanto de la teoría como de la práctica arquitectónica, tras la votación acordó su aprobación por cuatro votos a favor y uno en contra ${ }^{27}$.

El «avance facultativo» escrito por Josef Peterrade se concreta en la relación y la utilización de los materiales para su construcción. Este documento no aporta la visión tipológica de su autor. Tal circunstancia obliga a plantear el estudio del proyecto a partir de los planos. Si en todas las obras son una fuente importante para el análisis de conjunto en este caso es imprescindible por las razones mencionadas.

La planta baja del teatro (lámina III) se resuelve a partir de un rectángulo cuadrangular $(A B)$ inserto en otro rectangular cuyo eje $C D$ define la simetría del conjunto, en sentido longitudinal. Éste se organiza en una malla reticular en la que se trazan los cimientos, los accesos al primer piso y los elementos inscritos en el conjunto. La explicación de este diseño parte de la línea central en la que se traza la entrada al vestíbulo (1) delineada con cinco aberturas en el pórtico de acceso. A la derecha del eje CD se ubica el cuerpo de guardia (2) y a la izquierda se dispone el despacho de billetes (3). En la parte posterior del vestíbulo, tres vanos con escalinatas distribuyen las entradas centrales a los corredores (8) a las cajas de escaleras (6) y a los comunes (7). Los subterráneos (9) están dibujados en la sala y el escenario con sus respectivos pilares. Éste tiene sus entradas por la fachada posterior, así como sus escaleras de servicio. Los laterales del cuerpo principal se reservan a las tiendas (4) sus entradas y a los corredores.

25 Ibidem. Instancia firmada por Josef Peterrade. Madrid, 6 de marzo de 1830. «presentando además por un efecto de su gratitud a la Academia, donde ha sido matriculado y recibido lecciones de los Srs. Directores de Arquitectura, un chapitel Corintio, por si puede merecer algun lugar entre las obras de sus discipulos».

${ }_{26}$ Ibídem. Escrito de Josef Peterrade dando cuenta de su elección.Madrid 17 de marzo de 1830. Correspondiente al no 43. «Puerta y entrada de una plaza de Armas con registro y habitacion para una compañia de guardia adornada de Arquitectura robusta correspondiente al edificio. Planta, fachada y corte».

${ }_{27}$ Ibidem. Junta de examen reunida el 27 de marzo de 1830. En la junta ordinaria del 25 de abril de 1830, Josef Peterrade fue aprobado por la Academia. 


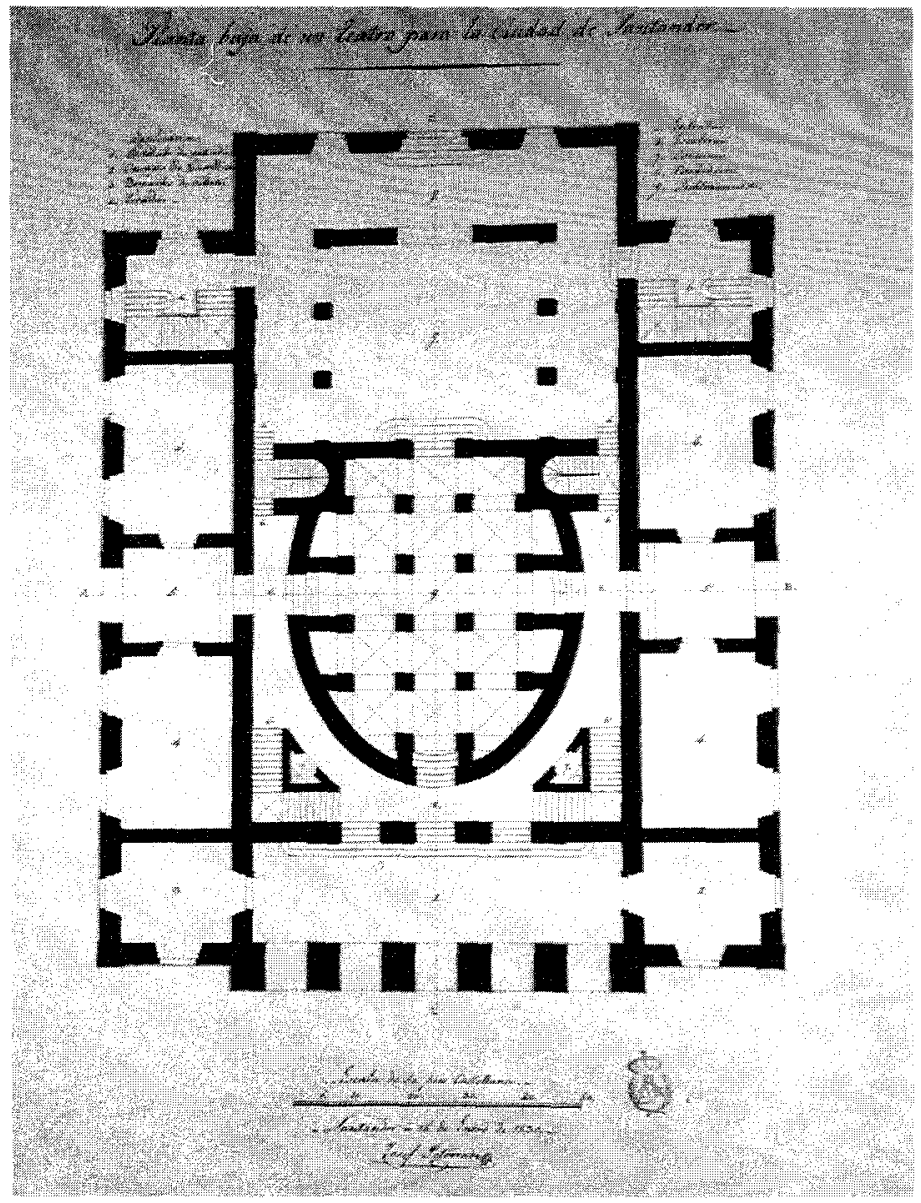

Lámina III. Josef Peterrade. Planta baja de un Teatro para la ciudad de Santander. 1830. Academia de San Fernando. A-3302.

Por ello en el primer piso del edificio (lámina IV) se proyecta el teatro. EI café (1) ocupa el espacio correspondiente al vestíbulo inferior. Las dos áreas de los ángulos, y las dependencias diseñadas en el eje $A B$, tienen la función de antesalas (2) para uso de los espectadores. A cada lado de las mismas se ubican las salas de juego (3) mientras la antesala destinada a los actores se traza en la línea $C D$, detrás del escenario. Además en la misma crujía se distribuyen los vestuarios de los hombres (10) y los destinados a las mujeres (11).

El auditorio de forma elíptica se resuelve en su perímetro interior por dos líneas divergentes en su unión con el lugar destínado a la orquesta 


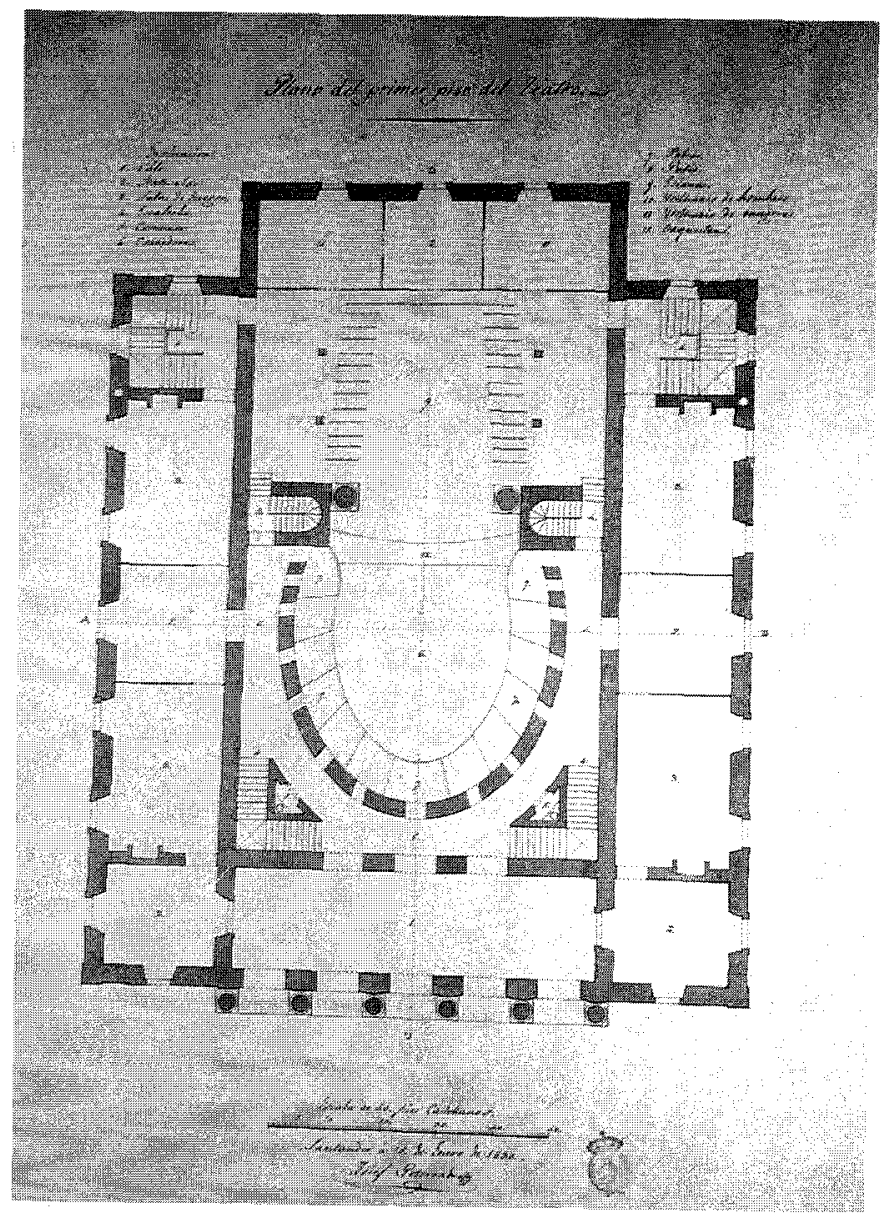

Lámina IV. Josef Peterrade. Plano del primer piso del Teatro. 1830. Academia de San Fernanóo. A-3303.

(12) y en su conjunción con la curva exterior se dibujan las separaciones de los palcos. Las escaleras del escenario ocupan el espacio interno lateral del arco de la embocadura. Sin embargo, hay que mencionar, que esta línea de cierre se fuerza y se reduce todavía más para la visual de los espectadores por la disposición de sendas columnas como se aprecia en el plano del corte longitudinal AB (lámina VIII).

En la sección del teatro por el eje CD (lámina IX) se aprecia la distribución de la sala en altura con cuatro pisos como si se tratase de palcos pero en el que no se trazan las separaciones y además se disponen en 


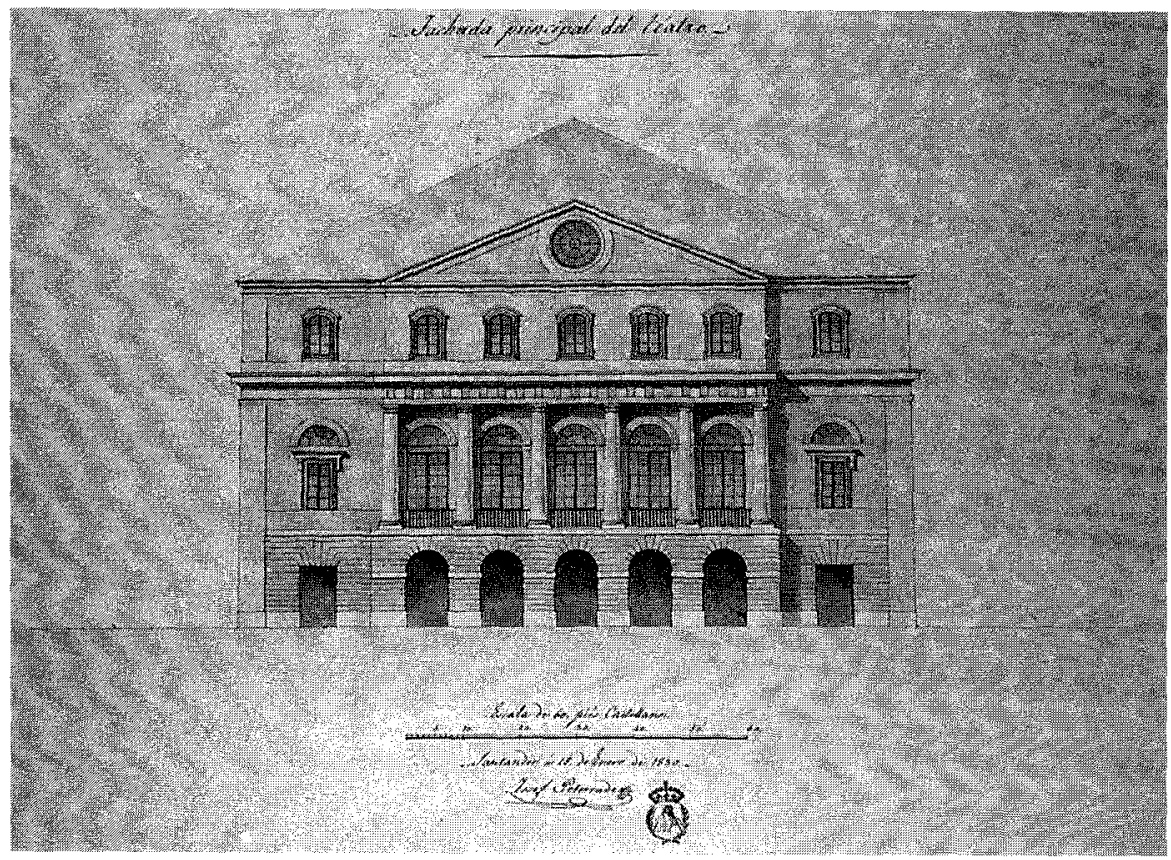

Lámina V. Josef Peterrade. Fachada principal. 1830. Academia de San Fernando. A-3304.

graderío. Peterrade recogía en el presupuesto la colocación de balaustradas de hierro en las delanteras de aquellos y la disposición de gradas en el patio hasta el lugar ocupado por la orquesta. Respecto al escenario se perfila la solución dada a los elementos de la maquinaría escénica tanto en altura como en el foso.

La relación del teatro con la ubicación en la ciudad se plantea como exenta. El elemento común unificador del exterior es el fajeado, que circunda todo el edificio hasta la primera imposta, roto en cada una de las esquinas por las pilastras que a su vez resaltan los macizos. El sistema de vanos se halla encuadrado por las cornisas marcando estructuralmente sensaciones de verticalidad y horizontalidad dentro de un acusado efecto volumétrico por el material de fábrica empleado.

Una suma de claves determinadas inscribe la fachada principal (lámina V) dentro de un lenguaje formal clasicista definido por un orden dórico, que ornamenta el piso principal. La cornisa de escaso vuelo refuerza el eje vertical jerárquico de la fachada, que comprende el frontón moldurado cuyo círculo central encierra una vidriera. Este elemento aumenta el recurso compositivo y elimina la sensación de pesadez de la cubierta. 
Además de las variaciones de los tamaños y las formas de los huecos, que parecen agilizar el repertorio formal, el autor distribuye en la fachada principal los vanos, que reflejan la luz en la rica serie de vidrieras y también se repite en las ventanas semicirculares de la fachada opuesta (lámina VI). La solución dada por Josef Peterrade a las fachadas laterales (lámina VII) refleja su dependencia del conjunto exterior y añade una clara funcionalidad. Ésta resalta por el juego de vanos que prácticamente ocupan todos los paños de la fachada, en la que destacan además de la portada central, las buhardillas del tejado.

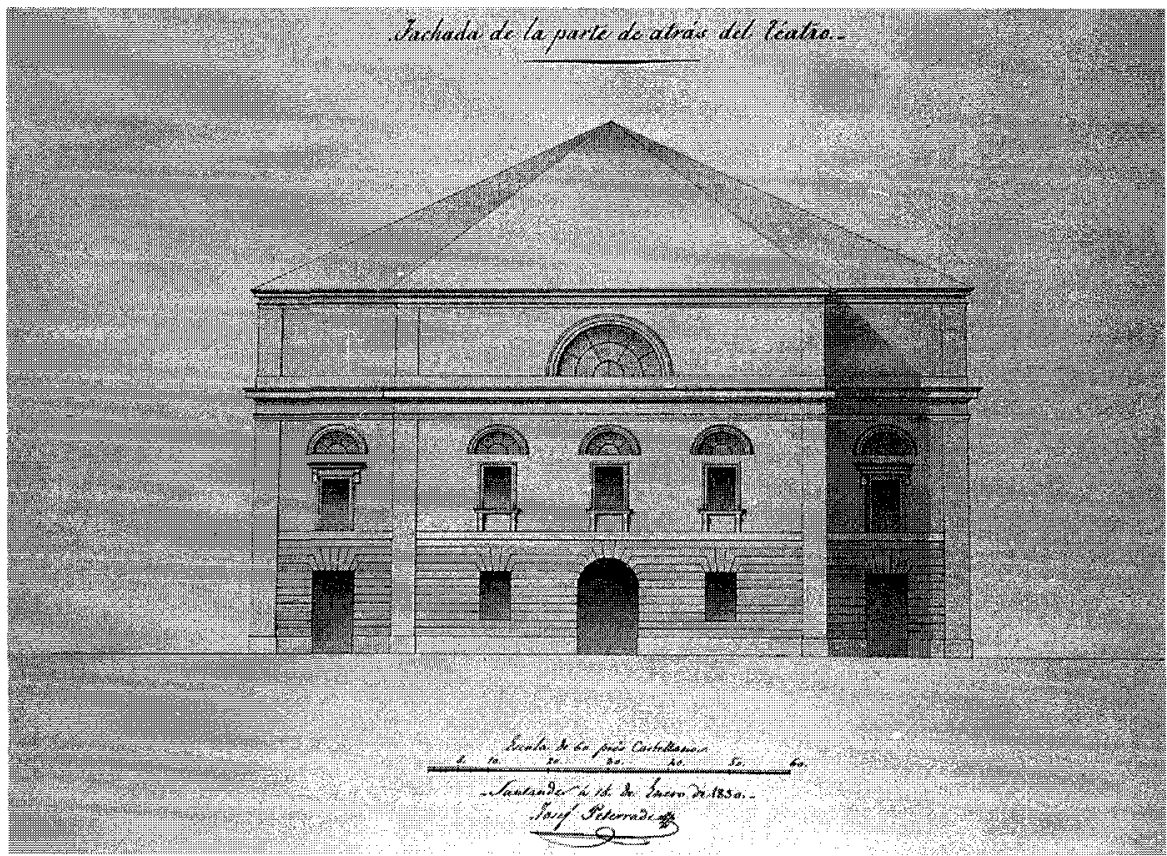

Lámina VI. Josef Peterrade. Fachada de la parte de atrás del teatro. 1830. Academia de San Fernando. A-3305.

Este proyecto, pensado para construirlo en la ciudad de Santander, resume la idea de una realidad práctica. Su definición exterior, monumental, conjuga una idea urbanística por la importancia del teatro como centro de las artes escénicas. Sin embargo, la solución dada al interior sugiere la dependencia de los planteamientos tipológicos anteriores a la fecha de su presentación a la Academia. Pero respecto a la organización de la fachada principal tenía un ejemplo construido, el teatro de Vitoria. 


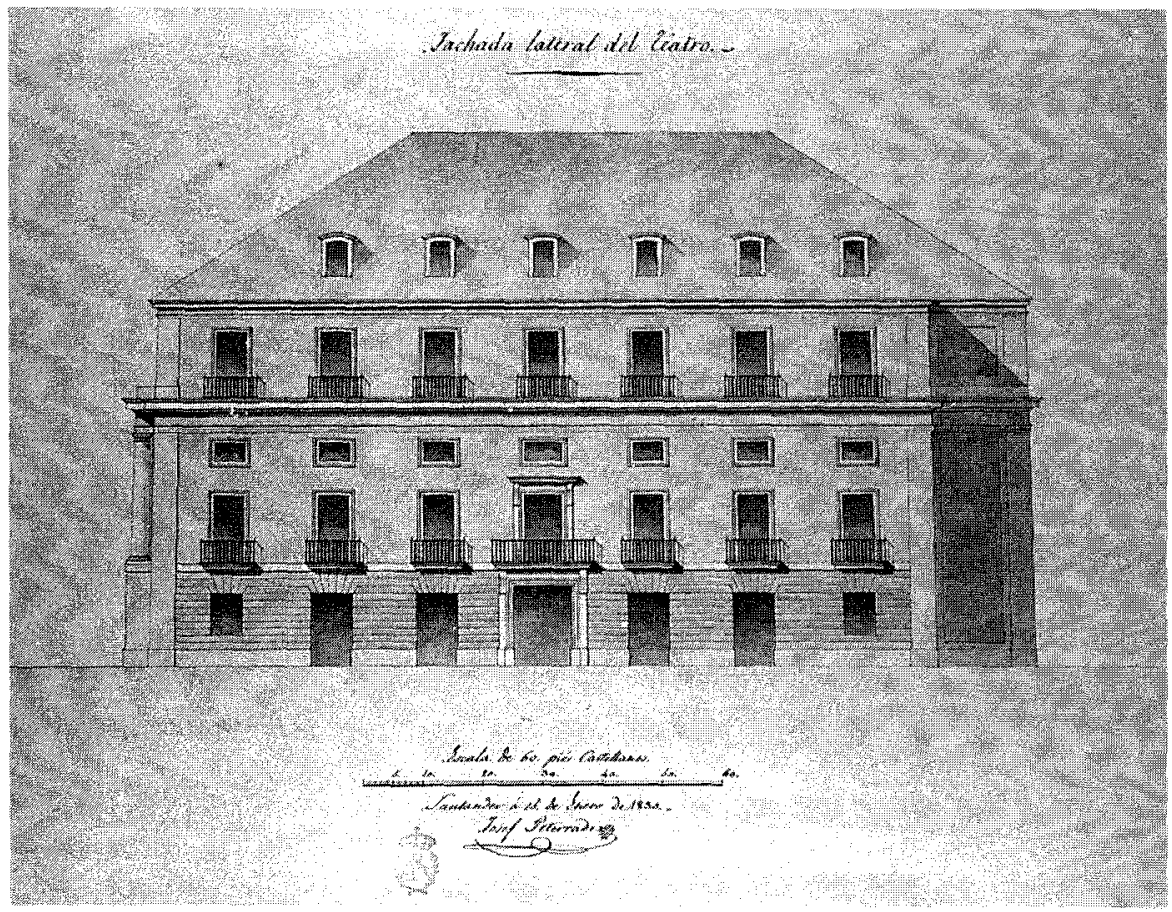

Lámina VII. Josef Peterrade. Fachada lateral del Teatro. 1830. Academia de San Fernando. A-3306.

\subsubsection{La visión tipológica teatral de Cirilo Salinas en 1832}

Este burgalés tenía veinticinco años cuando se presentó a las pruebas de examen de arquitecto. Había estudiado la Arquitectura con Joaquín Ignacio de Zunzunegui, arquitecto de la Academia de San Fernando. También se trasladó a Madrid para "perfeccionar sus estudios en las clases de Arquitectura y Matemáticas» ${ }^{28}$. Presentó ${ }^{29}$ como obra de pensado

\footnotetext{
${ }_{28}$ A.R.A.S.F. Leg. 9-7/2. Instancia firmada por Cirilo Salinas en Madrid el 26 de octubre de

29 Ibidem. Informe de la junta de la Comisión de Arquitectura del 30 de octubre de 1832. Aceptada esta primera obra, se le sortearon, en la junta ordinaria del 4 de noviembre de 1832, los tres asuntos para la prueba de repente. Cirilo Salinas eligió el $n^{2} 85$ «La Ermita de un Santuario con habitación para el Patrono o Administrador eclesiastico. Planta, fachada y corte. Superado este ejercicio, y reunida la junta de examen el 17 de noviembre de 1832, compareció ante dicha junta respondiendo con claridad a las preguntas de los examinadores. La junta le consideró apto por unanimidad de votos. La ratificación académica se efectuó, como era normativo en junta ordinaria, reunida el 16 de diciembre de 1832 .
} 1832. 
los planos de un Teatro para una capital con otras dependencias lúdicas y una completa e interesante memoria facultativa. En la que retomó y amplió la línea historicista marcada, en los primeros años del siglo XIX, por Juan Gómez y Pedro Simón de Urrutia. Una primera vía de análisis conduce a constatar el interés de Salinas por la génesis, evolución y dependencias de la tipología teatral y en concreto el estudio de la óptica y la acústica.

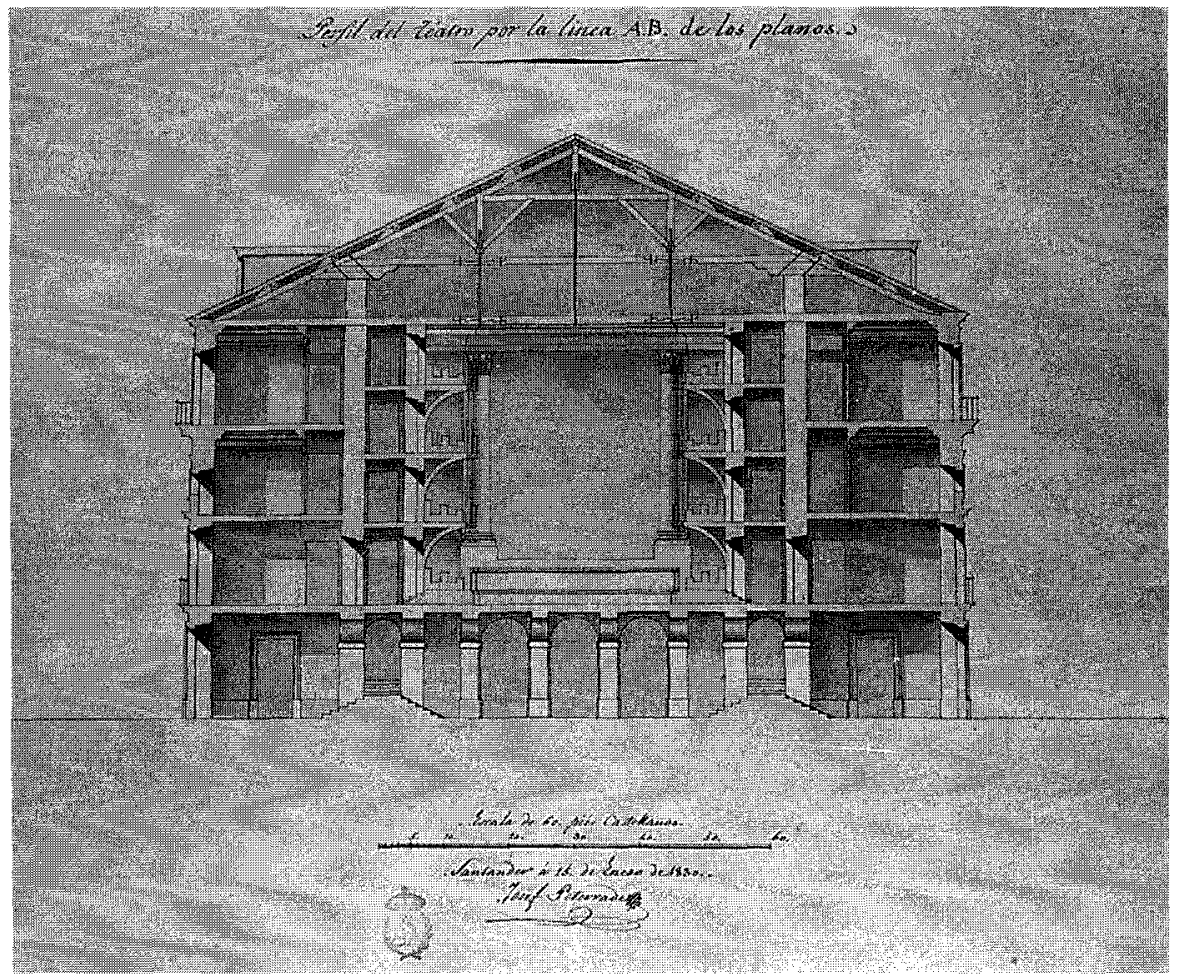

Lámina VIII. Josef Peterrade. Perfil del Teatro por la línea AB de la planta. 1830. Academia de San Fernando. A-3307.

La segunda línea nos permite observar la capacidad de respuesta de este aspirante a la teoría y a la práctica plasmada en su obra. El proyecto diseñado por Cirilo Salinas refleja una voluntad de síntesis arquitectónica y funcional, en la que prima la multiplicación de dependencias, dentro de un conjunto de dimensiones extraordinarias. Aunque en su traza afloran toda una serie de aportaciones italianas anteriores, es, particularmente significativa la lectura del burgalés, sobre el trazado del escenario, pensado para obras de gran aparato escénico, como las Óperas. 


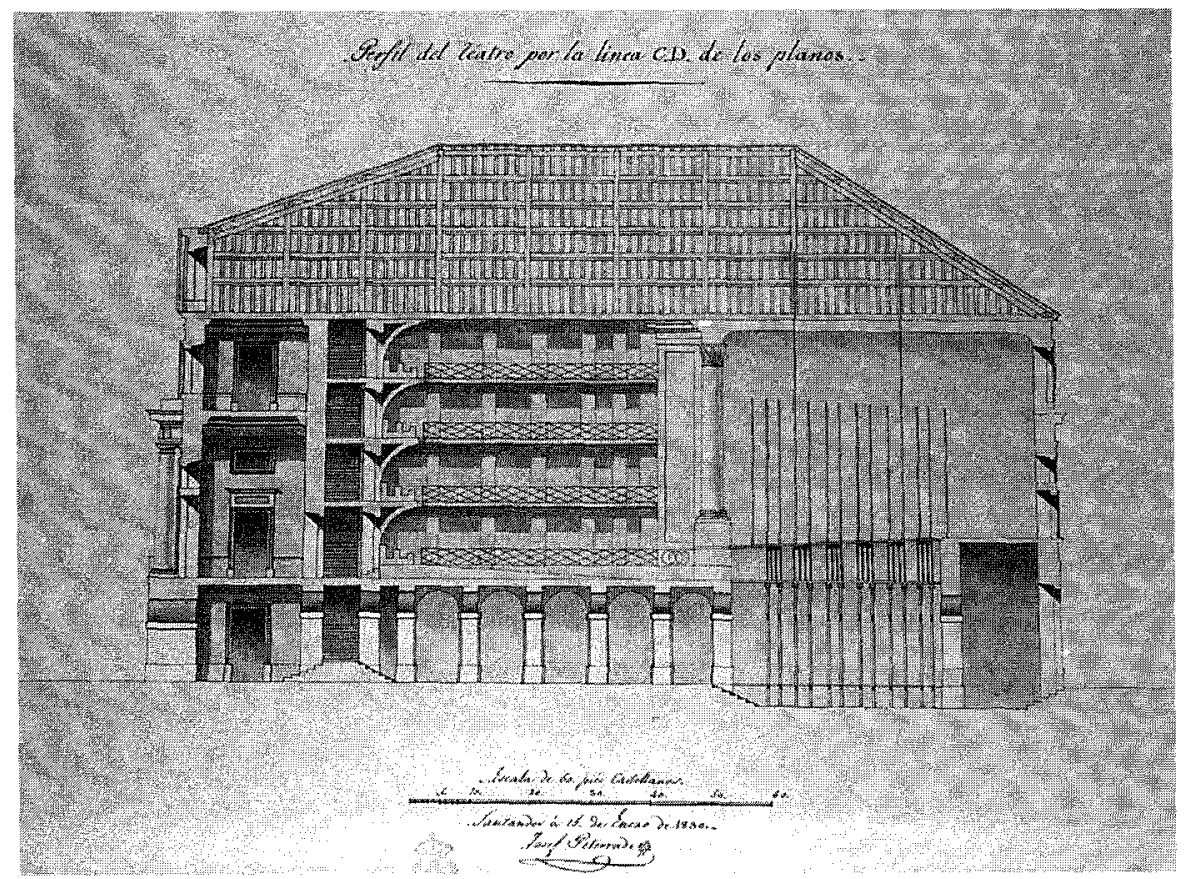

Lámina IX. Josef Peterrade. Perfil del Teatro por la línea CD de los planos. 1830. Academia de San Fernando. A-3308.

Un nuevo código lingüístico se conjuga en el proyecto de Salinas. Además de singularizar el conjunto, el autor aporta también su concepción de la curva del auditorio. Desde un punto de vista histórico se refería a la relación, que existe entre la disposición de los espectadores para ver con comodidad la representación y la distribución de los palcos en la vertical de la sala, repetida en los teatros modernos. Esta dependencia había conducido a los arquitectos a emplear «el círculo y la elipse por sí solas o combinadas con lineas rectas formando la herradura y otras figuras análogas" ${ }^{30}$.

Con relación a la idea propuesta en su proyecto, acerca de la figura de la sala, su elección ${ }^{31}$ no era la curva semicircular prolongada en forma

${ }^{30} \quad$ Ibidem. Memoria facultativa del proyecto de «Teatro público para una Capital con otros varios accesorios pertenecientes al mismo", firmada en Madrid el 29 de octubre de 1832 por Cirilo Salinas.

${ }^{31}$ Ibidem. Cirilo Salinas exponía que «la forma mas conveniente para la planta de un teatro es la de dos rectas que partiendo de la embocadura diverjan insensiblemente una pequeña cantidad y se hallen terminadas por un semicirculo, cuya figura es aun mucho mas conveniente para que 


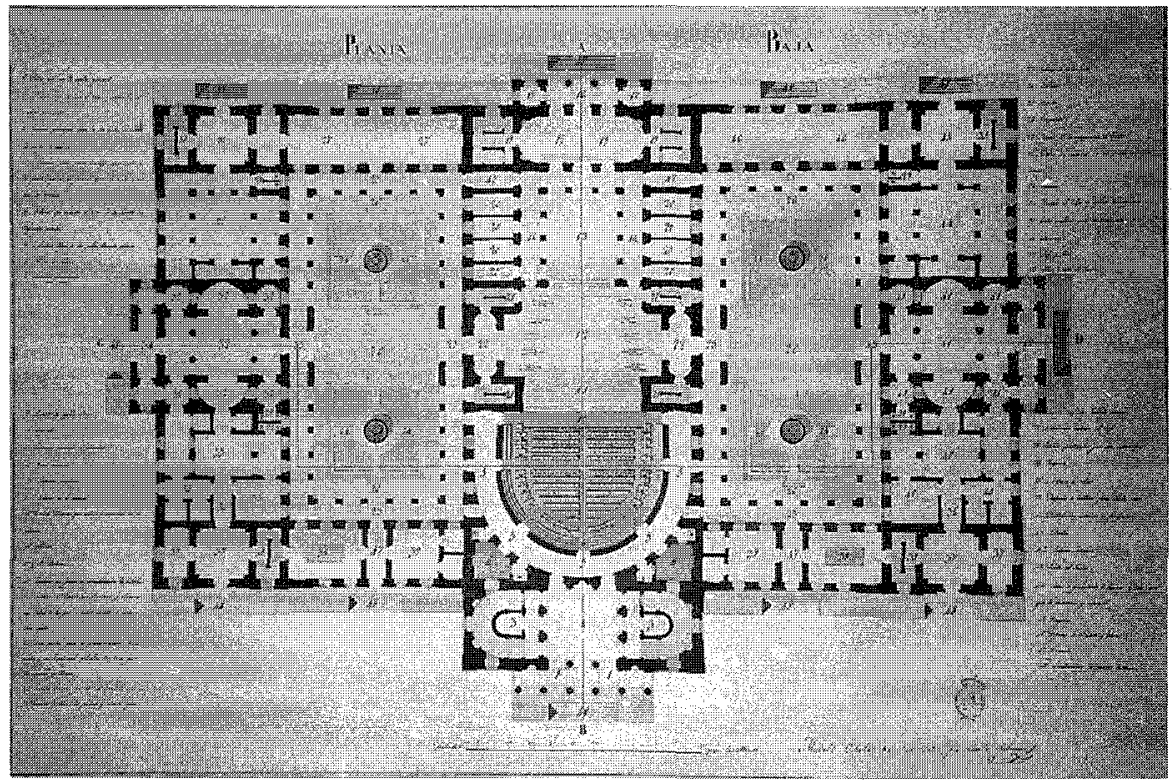

Lámina X. Cirilo Salinas. Planta baja del Teatro. 1832. Academia de San Fernando. A-3393.

de $\mathrm{U}$ sino una aproximación a la de herradura. Resuelta a partir de unas lineas de cierre, que se aprecian más claramente en el plano de la planta principal (lámina XI) por la distribución de los palcos. En este contexto, la solución de no colocar palcos de proscenio le permitió disponer un auditorio más ancho que largo al tener la linea de truncamiento, no en la embocadura sino en la linea del espacio reservado para la orquesta. De esta forma abría la visual de los laterales de la planta baja (lámina X) y conjugaba una acertada disposición de los espectadores que ocupaban tales plazas.

El rectángulo menor destaca, en el plano de la planta, por ser considerado por el autor como lugar central y eje simétrico del conjunto del edificio. La explicación del mismo se inicia en el pórtico (1) principal del teatro. En el vestíbulo (2) se distribuyen cuatro columnas, que enmarcan las extraordinarias escaleras (3) de dos tiros. Contiguos a las mismas, en el área de la curva con el ángulo recto, se ubican dos pequeños patios (4) y los comunes. 


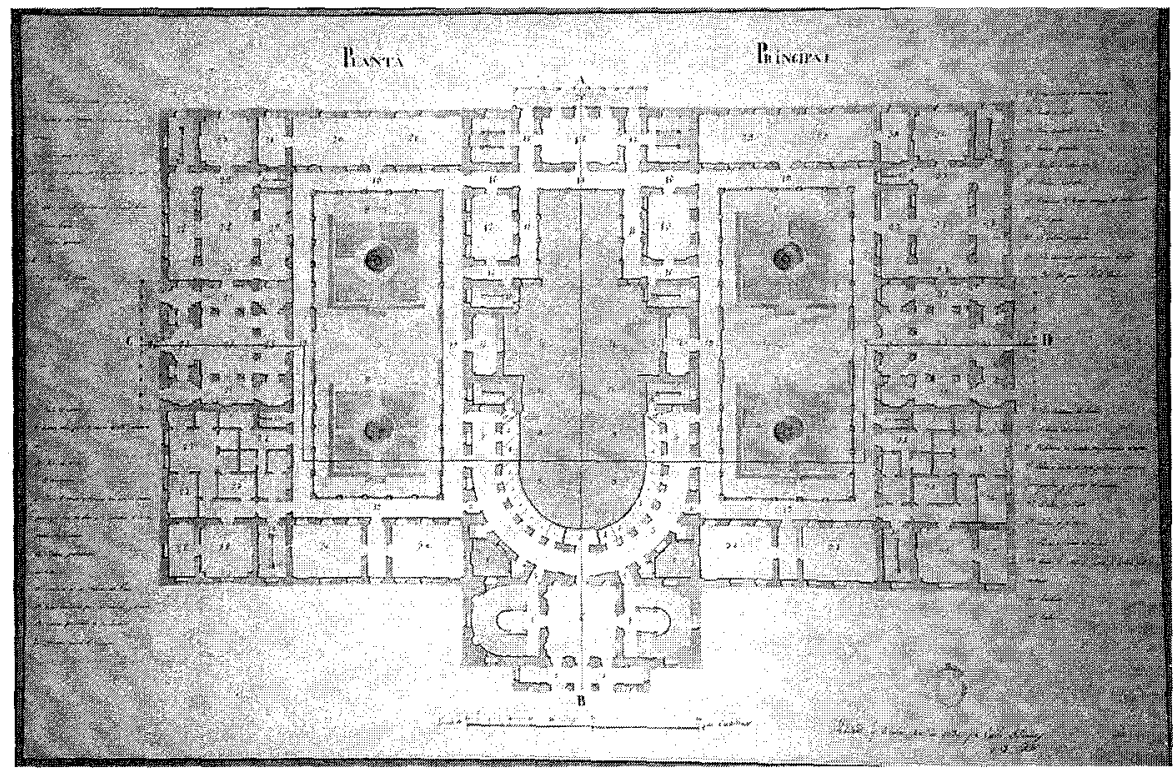

Lámina XI. Cirilo Salinas. Planta principal. 1832. Academia de San Fernando. A-3394.

Además de considerar la función de ventilación de los servicios, esas áreas abiertas se plantean igualmente para dar luz a las escaleras principales. Los cuatro patios mayores adquieren todavía más relevancia debido a su significación recreativa a la que se añade una estudiada ubicación entre el teatro y las alas del edificio, con sus galerías (23) abiertas a los jardines (23), a las fuentes (25) y a los tránsitos (26).

La importancia de los patios grandes se aprecia también en la multiplicación de los accesos a la sala y al escenario. En la primera se abren a la galería (5) o corredor del auditorio. Su distribución del interior, a partir del perímetro destinado a los espectadores, se clasifica en una primera línea de asientos colocados debajo de los palcos (6), una segunda con una fila de sillones (7), mientras el espacio curvo se reserva para las lunetas de segundo orden (9) y el resto del patio para las principales.

Este diseño tiene un interés especial en la proyección del escenario, pues su autor delinea dos, uno principal (12) y otro secundario (13). El primero dispone en sus ángulos cuatro escaleras (21) estudiadas tanto por su función como por las dimensiones y organización del palcoescenio. El área intermedia está destinada a salas de espera (22) y paso a los jardines. Las cajas de las primeras forman la línea interior de la embocadura. 
Contiguas a las posteriores y cerrando los laterales del segundo escenario se hallan los cuartos para los primeros actores (20) abiertos a la galería que lo circunda. Esta solución además de crear una interesante sensación de espacialidad permite la puesta en escena de óperas de gran aparato escenográfico. En la parte posterior tres vanos se abren a un amplio vestíbulo (15), al pórtico testero y a las porterías $(17,18)$.

Las dependencias de la maquinaría escénica $(27,28,30)$, comunes (29) y escaleras (31) son trazadas en la crujía de la fachada posterior y ángulo de la lateral izquierda; en la de la derecha se disponen las salas de preparación de lienzos, arreglo de bastidores (44), depósito para éstos y para los telones (46) y accesos. Los espacios rectangulares, con cuatro columnas y añadidos semicirculares, ubicados en la linea CD, corresponden a un café y a una fonda, junto a ellos se distribuyen sus elementos dependientes y sus ingresos.

En las alas de la fachada principal, además de los despachos de billetes (39) y de las amplias zonas de ingreso, se trazan también simétricamente dos salas de billar (38). El denominador común del conjunto proyectual es el teatro pues cada uno de los servicios está pensado y relacionado con él. El nexo entre la disponibilidad y la funcionalidad del diseño se plasma, tanto en las dependencias ideadas para la comodidad de los asistentes al espectáculo, como en las relativas a los actores y demás personas dependientes o relacionadas con el teatro.

Esta idea también se proyecta en la planta principal (lámina XI) y se repite el diseño de los elementos de acceso y distribuidores. En este piso se define como específico el trazado del balcón principal (7), el salón de descanso (6) y se delinea como lugar central el espacio reservado al palco real (5), a sus lados se disponen los dieciséis palcos particulares (4).

Cirilo Salinas traza en el plano del piso noble y en los laterales del escenario secundario, un salón para coristas (12) y otro para comparsas (13) reservando el área de la fachada trasera para la sala de juntas de los cómicos (18), sus alas para almacén de vestuarios (20) con sus oficinas (21) y taller de sastrería (39). A la fachada lateral se abren una serie de salones destinados a escuela de baile (22), de declamación (25) y de canto (35), estos dos se superponen a los espacios reservados en la planta baja para café y fonda, que también tienen sus salas reservadas para su servicio.

El plano de la sección (lámina XIII) muestra el perfil del pórtico, la repetición de las alturas de la portada y la aplicación en el vestíbulo y en el salón de descanso de los mismos órdenes arquitectónicos, que ornamentan la fachada. En relación con la sala se perfila claramente el desnivel del patio, la traza de la bóveda trastornada debajo del lugar reservado a la 


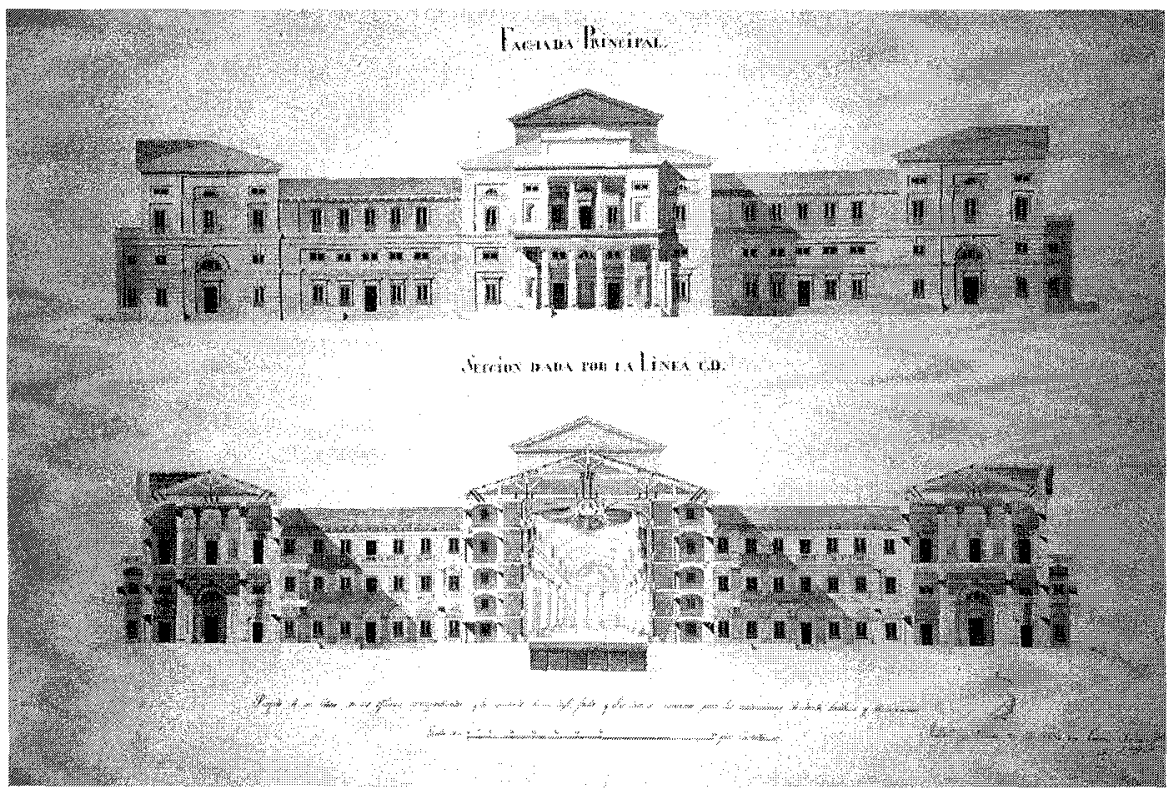

Lámina XII. Cirilo Salinas. Fachada principal y Sección dada por la línea CD. Academia de San Fernando. A-3395.

orquesta y la ordenación ornamental de la vertical de la sala. La disposición arquitectónica del perímetro del escenario le obliga a distribuir la maquinaría escénica en el foso y encima del arco de la embocadura.

Cirilo Salinas ubicaba su teatro en el centro de la ciudad ocupando una manzana y abierto en su frente a una plaza. El eje de simetría que regula la fachada principal (lámina XII) manifiesta la conjunción equilibrada y armoniosa del edificio. A pesar de la composición y el repertorio formal de inspiración clasicista esta fachada desprende una clara funcionalidad. El arquitecto resuelve los problemas de aireación con las diferentes series de vanos que a su vez aportan un ritmo compositivo al conjunto arquitectónico.

Su particularidad reside en los volúmenes laterales cuyas lineas de cierre se simplifican para no romper la centralidad de la portada principal. Resuelta con un pórtico de seis columnas dóricas, que aporta un casi imperceptible movimiento de verticalidad, definido en el piso principal por las dos columnas de orden corintio, en cuyo cornisamiento se sustenta la cartela. Este recurso, al mismo tiempo ornamental y funcional, permite resolver decorativamente la solución dada a la parte más complicada del teatro, la de las cubiertas, definida en su remate por un frontón. 


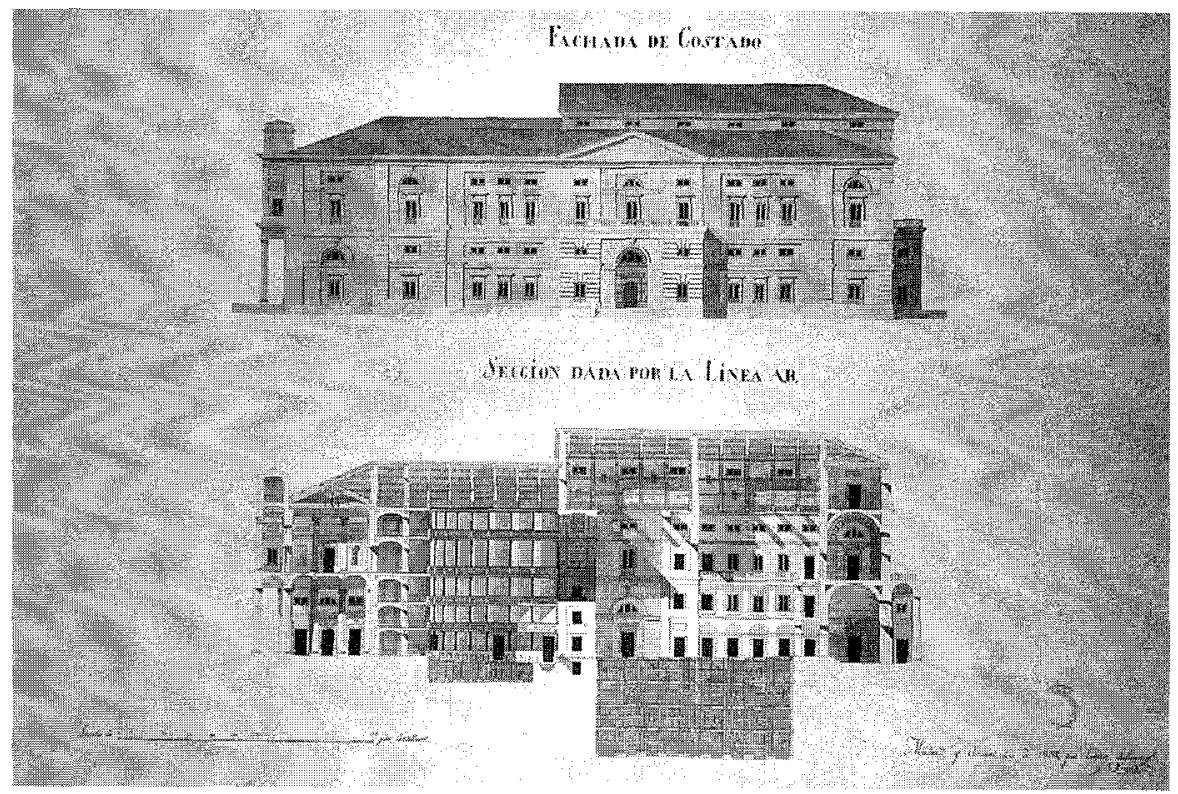

Lámina XIII. Cirilo Salinas. Fachada de costado y Sección dada por la línea AB. Academia de San Fernando. A-3396.

En resumen, la lectura de estos tres proyectos de teatro tiene en común la recurrencia al uso de un estilo clasicista, no sólo como signo preeminente del edificio, sino como indicador de una voluntad de mostrar su destino. En su relación con la ciudad el edificio se plantea aislado y las cuatro fachadas convenientemente jerarquizadas. La ordenación espacial, formal y ornamental va ganando en intensidad a medida que se acerca al centro de la fachada. El acento relevante recae en la portada principal en la que también se destaca el piso noble. Los tres diseños responden a una idea de edificio regular en el que se conjugan los principios clásicos de solidez, comodidad y belleza.

Los elementos divergentes se plantean directamente en el trazado de la planta. En primer lugar se constatan, como especificas, las medidas de cada uno de los conjuntos arquitectónicos. Paralelamente a la cuestión de las dimensiones se aprecia la reducción o multiplicación de dependencias anexas al lugar central del edificio definido por la sala y el escenario. Estos mismos espacios, aunque siguen un mismo planteamiento, el obligado por la tipología teatral, tienen trazas diferentes. A su vez derivan del diseño geométrico de la curva del auditorio, que a su vez condiciona la disposición de los espectadores, tanto en la planta como en la vertical del mismo; 
igualmente define el cierre de la embocadura, que también depende del escenario. Estos elementos forman parten de un conjunto de factores relacionados con la polémica generada por definir la curva ideal en la concepción del teatro moderno.

En síntesis hay que mencionar, dentro del quehacer censor de la Academia de Bellas Artes de San Fernando y respecto a los tres proyectos comentados, la visión abierta de la institución al considerarlos dignos de aprobación. A pesar de haber sido resueltos, a partir de las particularidades proyectuales de cada uno de los autores, en tres curvas y tres dimensiones distintas. 